\title{
POTENSI PENERAPAN PRODUKSI BERSIH DI PETERNAKAN SAPI PERAH CV. MARGO UTOMO KECAMATAN KALIBARU KABUPATEN BANYUWANGI
}

Potential of Clean Production Implementation at The CV. Margo Utomo Dairy Farm, Kalibaru Sub-district, Banyuwangi Regency

\author{
Elida Novita $^{1}{ }^{*}$, Ida Bagus Suryaningrat ${ }^{1)}$, Ega Daniati $^{1) *}$ \\ ${ }^{1)}$ Jurusan Teknik Pertanian, Fakultas Teknologi Pertanian, Universitas Jember \\ Jalan Kalimantan No. 37 Kampus Tegalboto, Sumbersari, Jember, 68121 \\ *E-mail: elida_novita.ftp@unej.ac.id, danidania412@gmail.com
}

\begin{abstract}
CV Margo Utomo dairy farm has approximately 99 cows. Livestock activities include feeding, cage cleaning, milking and livestock bathing. High feed and water requirements resultes high amounts of waste feed and waste produced. If wastewater discharged into channel, it could cause water pollution and could reduce environment. There were two types of waste water. The wastewater that disposed directly wastewater in to channel and the wastewater that settled in basin for three days. Steps of this research included field observation, secondary and primary data collection, problem identification, clean production alternatives identification, feasibility analysis and alternative selection based on priority scale of alternative clean production actions. Feasibility analysis includes technique, environment and economy. Assessment of feasibility based on assessment indicators in the form of questionnaires. This study used NPV, IRR, B / C Ratio, and PBP. There were three alternatives based clean production, that could be applied at the CV. Margo Utomo, such as biogas, water recycle, and cleaning pool for cows. Based on these alternatives, biogas was a best priority to applied in the CV. Margo Utomo dairy farm.
\end{abstract}

Keywords: biogas, clean production, dairy farm, wastewater

\section{PENDAHULUAN}

Berkembangnya usaha sapi perah nasional telah memberikan kontribusi kenaikan jumlah populasi dan produksi susu dari tahun ke tahun. Menurut Badan Pusat Statistik (2016) jumlah populasi sapi perah di Jawa Timur meningkat dari 255.947 ekor pada tahun 2015 menjadi 264.905 ekor pada tahun 2016. Pertambahan populasi tersebut mengakibatkan kebutuhan pakan dan air untuk kegiatan peternakan meningkat.

Pakan merupakan faktor produksi yang sangat penting bagi pemeliharaan ternak perah karena biaya untuk pakan mencapai $60-70 \%$ dari total biaya. Kebutuhan dasar seekor sapi perah terhadap air kurang lebih 40 liter/hari (akan bertambah apabila ukuran sapi perah lebih besar), sedangkan kebutuhan pakan hijau sebesar $10 \mathrm{~kg} / \mathrm{hari}$ (Ako, 2012). Kebutuhan pakan dan air yang tinggi tersebut mengakibatkan jumlah limbah yang dihasilkan tinggi.

Usaha peternakan sapi di Indonesia saat ini masih mementingkan produktifitas ternak tanpa mempertimbangkan aspek lingkungan. Satu ekor sapi dengan bobot badan 400-500 kg dapat menghasilkan limbah padat dan cair sebesar 27,5-30 $\mathrm{kg} / \mathrm{ekor} / \mathrm{hari}$. Limbah tersebut berupa limbah padat, cair, dan gas, ataupun sisa pakan (Putra, 2009).

Menurut Sumiarsa et al. (2011) karakteristik limbah cair peternakan memiliki bau yang khas, berwarna coklat keruh dengan suhu $25,5^{\circ} \mathrm{C}$, memiliki $\mathrm{pH}$ 8,57 , dengan kandungan bahan organik yang tinggi ditunjukkan dengan nilai BOD (biochemical oxygen demand) dan 
COD (chemical oxygen demand) yang tinggi yaitu $1250 \mathrm{mg} / \mathrm{liter}$ dan 3460 mg/liter. Air larian yang berasal dari kandang atau hasil penyiraman akan membanjiri lahan dan mengakibatkan pencemaran terhadap badan air. Dampak lain mengakibatkan pencemaran udara karena hasil penguraian bahan organik limbah ternak yang dibuang dengan cara ditumpuk dan menggunung di suatu tempat tanpa penanganan yang benar mengakibatkan bau dan berbahaya bagi kesehatan manusia (Sudiarto, 2008).

Menurut Kementerian Lingkungan Hidup Republik Indonesia (2017) produksi bersih merupakan suatu strategi pengelolaan lingkungan yang bersifat preventif, terpadu, dan diterapkan secara kontinyu pada proses produksi, produk, dan jasa untuk meningkatkan eko-efisiensi sehingga mengurangi resiko terhadap kesehatan manusia dan lingkungan. Produksi bersih tidak hanya menyangkut proses produksi, tetapi juga menyangkut pengelolaan seluruh daur hidup produksi, dimulai dari pengadaan bahan baku, pendukung proses operasi, hasil produksi, limbah, hingga sampai ke distribusi serta konsumsi.

Peternakan Sapi Perah CV. Margo Utomo terletak di Kecamatan Kalibaru, Kabupaten Banyuwangi. Jumlah sapi perah yang ada kurang lebih 99 ekor. Pada proses pemeliharaan hingga proses produksi, peternakan sapi perah $\mathrm{CV}$. Margo Utomo masih kurang memperhatikan efisiensi dalam penggunaan air. Limbah yang langsung dibuang ke lingkungan tanpa diolah akan mengkontaminasi udara, air dan tanah sehingga menyebabkan polusi. Beberapa gas yang dihasilkan dari limbah ternak dapat melemahkan daya dukung tanah sehingga menyebabkan polusi bau. Pada air, mikroorganisme patogenik (penyebab penyakit) yang berasal dari limbah ternak akan mencemari lingkungan perairan. Salah satu yang sering ditemukan yaitu bakteri Salmonella sp. (Racmawati, dalam
Hardiyanto et al., 2013). Limbah cair yang berasal dari pembersihan kandang hanya ditampung, setelah penuh langsung dibuang ke perkebunan setiap tiga hari sekali atau dibuang ke sungai tanpa dilakukan penanganan, sehingga diperlukan pengelolaan lingkungan yang preventif dan terpadu dengan penerapan produksi bersih.

\section{METODE PENELITIAN}

\section{Alat dan Bahan}

Alat yang digunakan dalam penelitian ini adalah timbangan, kuisioner, kamera dan alat tulis. Analisis menggunakan alat TDS meter, oven, Turbiditimeter TN-100, Reaktor COD HI 839800, Spektofotometer HI 8309 dan botol winkler. Bahan yang digunakan adalah pakan ternak, air, dan limbah yang dihasilkan di peternakan sapi perah CV. Margo Utomo Kecamatan Kalibaru Kabupaten Banyuwangi. Bahan kimia yang digunakan adalah larutan Magan Sulfat 36,4\%, larutan alkali iodida azida 66\%, larutan natrium tiosulfat, $\mathrm{H}_{2} \mathrm{SO}_{4}$ pekat $98 \%$ dan Reagen COD HR (High Range).

\section{Tahapan Penelitian}

Observasi Lapang

Observasi lapang dilakukan untuk mengetahui bagaimana kegiatan yang dilakukan di peternakan sapi perah CV. Margo Utomo untuk setiap harinya. Kegiatan-kegiatan tersebut dapat menyebabkan banyaknya limbah terbuang dan pencemaran terhadap lingkungan.

\section{Pengumpulan Data Primer dan Sekunder}

Penelitian ini menggunakan metode deskriptif kualitatif, yaitu penenelitian yang menghasilkan data kualitatif dan kemudian dideskripsikan. Data yang digunakan dalam penelitian ini adalah data sekunder dan data primer. Berikut merupakan penjelasan data primer dan data sekunder. 
Sumber data primer diperoleh dengan melakukan pengamatan langsung dan wawancara dipeternakan sapi perah CV. Margo Utomo. Data primer yang dibutuhkan adalah pakan, air yang digunakan, limbah yang dihasilkan, SOP peternakan, jenis pakan yang diberikan, konsumsi/hari, jumlah sapi, harga pakan/hari, jumlah pekerja dan jam hari kerja.

Data sekunder diperoleh berdasarkan studi pustaka. Studi pustakan dilakukan melalui buku, jurnal ilmiah, serta sumber dari internet.

\section{Analisis Data}

Identifikasi Tingkat Pencemaran Limbah Cair Peternakan

Limbah cair yang akan dianalisis karekteristiknya merupakan limbah cair langsung buang yang keluar dari saluran pembuangan dan limbah cair tampungan setelah tiga hari di tampung pada bak penampungan limbah cair. Pengambilan sampel dilakukan pagi hari pada pukul 09.00 WIB.

\section{Analisis Neraca Massa Peternakan}

Identifikasi neraca massa digunakan untuk mengetahui banyaknya input yang digunakan dan output yang dihasilkan pada kegiatan di peternakan. Input dan output tersebut kemudian digunakan untuk mengetahui berapa banyak pemberian pakan yang dilakukan dan kebutuhan pakan yang seharunya diberikan.

\section{Identifikasi Permasalahan dan Alternatif Tindakan Produksi Bersih} Identifikasi permasalahan dilakukan untuk mengetahui masalah yang terjadi di peternakan CV. Margo Utomo. Permasalahan-permasalahan tersebut akan diketahui sehingga diperoleh alternatif untuk diberikan pada peternakan sapi perah CV. Margo Utomo.

\section{Pemilihan Alternatif Berdasarkan Analisis} Teknis, Lingkungan, dan Ekonomi

Pemilihan alternatif berdasarkan analisis teknis, lingkungan, dan ekonomi dilaksanakan untuk memilih alternatif yang paling berpotensi untuk diterapkan. Analisis kelayakan ekonomi menggunakan metode Net Present Value (NPV), Internal Rate of Return (IRR), Net Benefit Cost Ratio (B/C Ratio), dan Pay Back Period (PBP). Kelayakan teknis dan lingkungan diperoleh dengan memberikan kuisioner kepada pemilik dan pekerja di peternakan Margo Utomo.

\section{Penentuan Skala Prioritas}

Penentuan skala prioritas dilakukan dengan melakukan penilaian $(1,2$ dan 3$)$ pada masing-masing alternatif produksi bersih. Setelah dilakukan penilaian pada setiap opsi berdasarkan aspek teknik, lingkungan, dan ekonomi kemudian dijumlahkan dan dilakukan peringkingan pada masing-masing alternatif.

\section{HASIL DAN PEMBAHASAN}

\section{Identifikasi Tingkat Pencemaran Limbah Cair Peternakan}

Di peternakan sapi perah CV. Margo Utomo, terdapat dua jenis limbah yang akan dianalisis karakteristikya yaitu limbah cair peternakan dan limbah cair peternakan setelah di tampung 3 hari. Karakteristik limbah cair peternakan yang berasal dari kegiatan pembersihan kandang ditunjukkan pada Tabel 1 dan 2.

Berdasarkan Tabel $\mathbf{1}$ dan 2, diketahui bahwa pada parameter suhu, $\mathrm{pH}$, TDS (total dissolved solid), TSS (total soluble solid), kekeruhan, COD (chemical oxygen demand) dan BOD (biochemical oxygen demand) limbah cair langsung dan setelah dilakukan penampungan selama tiga hari tidak memenuhi standar baku mutu limbah cair yang sudah ditetapkan oleh Menteri Lingkungan Hidup Nomor 5 Tahun 2014. Limbah cair dari kegiatan pembersihan kandang tersebut tidak layak 
untuk dibuang secara langsung ke lingkungan. Limbah cair tersebut masih melebihi ambang batas sehingga perlu adanya penanganan limbah cair lebih lanjut sebelum dibuang ke lingkungan.

Tabel 1. Karakteristik limbah cair peternakan

\begin{tabular}{lccc}
\hline Parameter & $\begin{array}{c}\text { Limbah } \\
\text { cair } \\
\text { peternakan }\end{array}$ & $\begin{array}{c}\text { Baku } \\
\text { mutu }\end{array}$ & Satuan \\
\hline Suhu & 23,4 & - & ${ }^{\circ} \mathrm{C}$ \\
$\mathrm{pH}$ & 8,1 & $6 \mathrm{sd} 9$ & - \\
TDS & 1307 & - & $\mathrm{mg} / \mathrm{l}$ \\
TSS & 508,4 & 100 & $\mathrm{mg} / \mathrm{l}$ \\
Kekeruhan & 476,8 & - & $\mathrm{NTU}$ \\
COD & 2134 & 200 & $\mathrm{mg} / \mathrm{l}$ \\
BOD & 1203 & 100 & $\mathrm{mg} / \mathrm{l}$ \\
\hline
\end{tabular}

Sumber : Data primer diolah (2018)

Keterangan: TDS (total dissolved solid), TSS (total soluble solid), kekeruhan, COD (chemical oxygen demand) dan BOD (biochemical oxygen demand)

Tabel 2. Karakteristik limbah cair peternakan setelah ditampung 3 hari

\begin{tabular}{lccc}
\hline Parameter & $\begin{array}{c}\text { Limbah cair } \\
\text { peternakan } \\
\text { di tampung } 3 \\
\text { hari }\end{array}$ & $\begin{array}{c}\text { Baku } \\
\text { mutu }\end{array}$ & Satuan \\
& 25,2 & - & ${ }^{\circ} \mathrm{C}$ \\
Suhu & 7,3 & $6 \mathrm{sd} 9$ & - \\
pH & 191,0 & - & $\mathrm{mg} / 1$ \\
TDS & 304,4 & 100 & $\mathrm{mg} / \mathrm{l}$ \\
TSS & 210,2 & - & $\mathrm{NTU}$ \\
Kekeruhan & 1300 & 200 & $\mathrm{mg} / \mathrm{l}$ \\
COD & 406,4 & 100 & $\mathrm{mg} / \mathrm{l}$ \\
BOD &
\end{tabular}

Sumber: Data primer diolah (2018)

Keterangan: TDS (total dissolved solid), TSS (total soluble solid), kekeruhan, COD (chemical oxygen demand) dan BOD (biochemical oxygen demand)

\section{Analisis Neraca Massa Peternakan}

Jenis pakan yang diberikan di peternakan sapi perah CV. Margo Utomo berupa hijauan (batang tanaman jagung), ampas tahu, dan konsentrat. Standar batang tanaman jagung yang ditetapkan oleh peternakan sapi perah CV. Margo
Utomo kepada supplier yaitu batang jagung tidak terlalu tua dan muda, tidak kering serta tidak busuk. Standar kualitas untuk ampas tahu yang ditetapkan oleh peternakan CV. Margo Utomo yaitu tidak bau, tidak ada ulat dan cacing, serta berwarna putih bersih. Pemberian pakan di peternakan CV. Margo Utomo dilakukan enam kali dalam sehari. Jadwal pemberian pakan sapi perah di peternakan Margo Utomo dapat dilihat pada Tabel 3.

Tabel 3. Jadwal pemberian pakan di peternakan sapi perah CV. Margo Utomo

\begin{tabular}{|c|c|c|c|c|}
\hline \multirow[b]{2}{*}{$\begin{array}{c}\text { Pembe } \\
\text {-rian } \\
\text { pakan }\end{array}$} & \multirow[b]{2}{*}{$\begin{array}{l}\text { Jenis } \\
\text { pakan }\end{array}$} & \multicolumn{3}{|c|}{ Jumlah } \\
\hline & & $\begin{array}{c}\text { Hijauan } \\
(\mathrm{Kg})\end{array}$ & $\begin{array}{c}\text { Konsentrat } \\
(\mathrm{Kg})\end{array}$ & $\begin{array}{c}\text { Ampas } \\
\text { tahu } \\
(\mathrm{Kg})\end{array}$ \\
\hline \multirow{2}{*}{ I } & $\mathrm{H}, \mathrm{K}$, dan & & & \multirow{3}{*}{342} \\
\hline & $\mathrm{AT}$ & 387,95 & 99 & \\
\hline II & $\mathrm{H}$ dan $\mathrm{K}$ & 297 & 50,5 & \\
\hline III & $\mathrm{H}$ dan $\mathrm{K}$ & 298,2 & 50,5 & \multirow{5}{*}{342} \\
\hline \multirow{2}{*}{ IV } & $\mathrm{H}, \mathrm{K}$, dan & & & \\
\hline & $\mathrm{AT}$ & 411,3 & 99 & \\
\hline V & $\mathrm{H}$ dan $\mathrm{K}$ & 316,6 & 50,5 & \\
\hline \multirow[t]{2}{*}{ VI } & $\mathrm{H}$ dan $\mathrm{K}$ & 368 & 50,5 & \\
\hline & $\begin{array}{c}\text { TOTAL } \\
\text { (Kg/hari) }\end{array}$ & 2079,05 & 400 & 684 \\
\hline
\end{tabular}

Sumber : Data primer diolah (2018)

Keterangan: H : hijauan (batang tanaman jagung), $\mathrm{K}$ : konsentrat, AT: ampas tahu

Satu kali pemberian pakan untuk sapi laktasi berupa hijauan (batang tanaman jagung) sebanyak 7,6 kg/sapi, konsentrat $2 \mathrm{~kg} / \mathrm{sapi}$, dan ampas tahu 7,6 $\mathrm{kg} / \mathrm{sapi}$. Sapi dara diberikan hijauan (batang tanaman jagung) sebanyak 2,3 kg /sapi, konsentrat $0,5 \mathrm{~kg} / \mathrm{sapi}$, dan sisa pakan sebanyak 6,7 kg/sapi, serta sapi pedet diberikan hijauan $0,75 \mathrm{~kg} / \mathrm{sapi}$ dan konsentrat $0,2 \mathrm{~kg} / \mathrm{sapi}$.

Menurut Peraturan Menteri Pertanian (2006) tentang pedoman pembibitan sapi perah yang baik pakan hijauan diberikan 2-3 kali sehari yaitu pagi dan siang hari sesudah pemerahan. Pakan hijauan diberikan sebanyak $\pm 10 \%$ berat badan. Pakan konsentrat diberikan dalam 
keadaan kering, sesudah pemerahan 1-2 kali sebanyak 1,5-3,0 \% dari berat badan, dan air minum disediakan secara tidak terbatas (ad libitum).

Tabel 4 menunjukkan pemberian pakan yang diberikan peternakan $\mathrm{CV}$. Margo Utomo masih belum memenuhi kebutuhan pakan dari sapi laktasi, dara, dan pedet berdasarkan berdas Peraturan Menteri Pertanian (2006). Kebutuhan pakan tersebut diperoleh dari $10 \%$ dari berat badan sapi. Oleh karena itu, diperlukan penambahan hijauan dan konsentrat untu setiap harinya. Khusus untuk sapi laktasi diberikan tambahan berupa ampas tahu.

Pemberian air minum di peternakan sapi perah CV. Margo Utomo dilakukan secara adlibitum (air tersedia secara terus menerus). Hal tersebut sesuai dengan pendapat Putra (2009), yaitu air minum harus ada atau tersedia karena air mempunyai fungsi vital. Air tersebut berfungsi sebagai zat pelarut dan pengangkut zat makanan, membantu proses pencernaan, penyerapan, dan pembuangan hasil metabolisme, memperlancar reaksi kimia dalam tubuh, serta pengatur suhu tubuh.

Tabel 4. Pakan yang diberikan dan kebutuhan pakan

\begin{tabular}{|c|c|c|c|c|c|}
\hline Sapi & Pakan & $\begin{array}{c}\text { Berat } \\
\text { sapi } \\
(\mathrm{Kg})\end{array}$ & $\begin{array}{c}\% \\
\text { dari } \\
\text { berat } \\
\text { sapi }\end{array}$ & $\begin{array}{c}\text { Pakan } \\
\text { yang } \\
\text { diberikan } \\
\text { (kg/hari) }\end{array}$ & $\begin{array}{c}\text { Kebutuhan } \\
\text { pakan } \\
\text { (Kg/hari) }\end{array}$ \\
\hline \multirow{3}{*}{ Laktasi } & $\mathrm{H}$ & \multirow{3}{*}{400} & 10 & 36,8 & 40 \\
\hline & $\mathrm{K}$ & & 3 & 8 & 12 \\
\hline & AT & & & 15,2 & \\
\hline \multirow{3}{*}{ Dara } & $\mathrm{H}$ & \multirow{3}{*}{450} & 10 & 54 & 45 \\
\hline & $\mathrm{K}$ & & 3 & 4 & 13,5 \\
\hline & AT & & & & \\
\hline \multirow{3}{*}{ Pedet } & $\mathrm{H}$ & \multirow{3}{*}{60} & 10 & 4,5 & 6 \\
\hline & $\mathrm{K}$ & & 3 & 1,2 & 1,8 \\
\hline & AT & & & & \\
\hline
\end{tabular}

Sumber : Data primer diolah (2018)

Keterangan: $\mathrm{H}$ : hijauan (batang tanaman jagung), $\mathrm{K}$ : konsentrat, AT: ampas tahu

\section{Sanitasi}

Sanitasi adalah suatu kegiatan yang meliputi kebersihan kandang dan lingkungannya (Departemen Pertanian, 2000). Sanitasi yang dilakukan di peternakan sapi perah CV. Margo Utomo meliputi sanitasi kandang, sanitasi sapi perah dan sanitasi peralatan pemerahan susu.

\section{Sanitasi Kandang}

Sanitasi kandang yang dilakukan dipeternakan sapi perah CV. Margo Utomo sudah terbilang baik. Hal tersebut terbukti dengan keadaan kandang yang dijaga agar tetap bersih. Sistem perkandangan yang ada di peternakan sapi perah CV. Margo Utomo beratapkan genting, dengan lantai semen, pengikat terbuat dari besi, tidak ada sekat antara dinding, mudah dalam pembersihan, lantai dibuat lebih tinggi, berjarak \pm 5 meter dari pemukiman, tersedia tempat penampungan kotoran dan limbah/ sisa pakan serta saluran pembuangan air. Menurut Departemen Pertanian (2000) kandang sapi perah harus memberikan kenyamanan ternak yaitu memiliki ventilasi yang cukup, mudah dibersihkan, tidak ada genangan, serta berjarak \pm 5 meter dari pemukiman.

\section{Sanitasi Sapi}

Pemandian sapi perah di CV. Margo Utomo dilakukan 2 kali dalam seminggu / jika ternak benar-benar dalam keadaan kotor. Pemandian sapi dilakukan dengan menggunakan selang dan kemudian digosok dengan menggunakan alat yang terbuat dari lempengan besi untuk mengilangkan kotoran ternak yang telah kering dan menempel pada kulit sapi. Hal tersebut tidak sesuai dengan anjuran Departemen Pertanian tahun 2000 yaitu ternak harus dimandikan sebanyak dua kali sehari pagi dan siang hari sebelum dilakukan pemerahan. Namun di peternakan sapi perah CV. Margo Utomo, pemandian ternak hanya dilakukan jika ternak sudah benar-benar kotor. Sapi perlu 
dimandikan pada pagi hari, karena biasanya pada malam hari sapi penuh dengan kotoran yang menempel pada tubuhnya (Ako, 2012). Sapi yang selalu bersih akan terhindar dari beberapa penyakit dan nafsu makan akan meningkat. Sapi yang kulitnya bersih, air keringatnya akan keluar dengan lancar, pengaturan panas tubuhnya akan sempurna, dan parasit kulit yang menyebabkan penyakit pada kulit tidak mudah terinfeksi.

\section{Peralatan Pemerahan}

Pembersihan peralatan pemerahan susu yang meliputi cooling, ember, saringan, gelas ukur, dan timba susu dilakukan dengan mencucinya dengan sabun dan kemudian dibilas. Hal tersebut tidak sesuai dengan anjuran Departemen Pertanian tahun 2000 yang mengharuskan pembersihan peralatan pemerahan dilakukan dengan menggunakan air panas.

\section{Identifikasi Alternatif Produksi Bersih}

Berdasarkan pada identifikasi permasalahan di peternakan sapi perah CV. Margo Utomo, maka terdapat alternatif yang dapat diterapkan. Alternatif produksi bersih tersebut adalah biogas, daur ulang air dengan sistem penyaringan dan pengendapan serta kolam pemandian ternak dan pembersihan alas ternak.

\section{Biogas}

Pada alternatif ini, biogas yang dihasilkan tidak dijual sehingga tidak menghasilkan profit. Tetapi pada alternatif ini biogas diasumsikan menggantikan bahan bakar gas LPG yang dibeli oleh perusahaan $\mathrm{CV}$. Margo Utomo setiap satu bulan sekali.

\section{Daur Ulang Air}

Penggunaan air yang banyak di peternakan CV. Margo Utomo untuk kegiatan pembersihan kandang dan pemandian ternak mengakibatkan pemborosan dalam penggunaan air. Jumlah limbah cair yang dihasilkan kurang lebih 6500 liter/hari. Tindakan yang dapat dilakukan untuk menghemat air adalah dengan melakukan daur ulang air dengan cara filtrasi.

Kolam Pemandian Ternak dan Pembersihan Alas Ternak

Rancangan kolam pemandian ternak ini didasarkan pada bangunan pemandian ternak yang terdapat pada saluran irigasi. Kolam pemandian dan pembersihan ternak ini memiliki ukuran panjang $\mathrm{x}$ lebar $\mathrm{x}$ tinggi yaitu $5,35 \mathrm{~m} \mathrm{x} \mathrm{3,30} \mathrm{m}$ dan 1,20 $\mathrm{m}$. Ukuran tersebut diperoleh dari 3 pertimbangan ukuran yaitu tempat perah yang terdapat dipeternakan Margo Utomo, sapi berukuran paling besar yang terdapat di CV. Margo Utomo dan alas ternak yang digunakan di peternakan CV. Margo.

\section{Analisis Berdasarkan Aspek Teknis, Lingkungan, dan Ekonomi}

Analisis berdasarkan aspek teknis, lingkungan dan ekonomi dilakukan dengan mengambil kuisioner. Kuisioner diberikan pada 30 responden yang bekerja pada bagian peternakan, kebun, dan baker.

\section{Analisis Teknis}

Analisis teknis merupakan analisis yang digunakan untuk mengetahui apakah penerapan produksi bersih tersebut mudah untuk dilaksanakan atau tidak. Jumlah indikator berdasarkan aspek teknis terdapat 17 indikator meliputi jumlah pekerja, pendidikan,umur, tenaga ahli, ketersediaan tenaga ahli, pemantauan/penilaian kinerja, pemeriksaan kesehatan karyawan, pelatihan ketenaga kerjaan, jaminanan kesehatan dan keselamatan kerja, kemudahan kontruksi, kemudahan operasi, sumber air, sistem pengairan, penggunaan mesin, ketersediaan alat dan bahan baku, serta lokasi. Pada penilaian indikator teknis, skor tertinggi adalah 3 dan terendah adalah satu. Skor 3 menunjukkan jika alternatif sangat mudah diterapkan secara teknis, skor 2 menunjukkan jika alternatif cukup mudah untuk diterapkan, dan 1 
menunjukkan jika alternatif sulit untuk diterapkan. Tabel 5 merupakan tabel hasil analisis teknis dari alternatif biogas, daur ulang air, dan kolam pemandian ternak.

Tabel 5. Hasil analisis teknis

\begin{tabular}{lcc}
\hline Alternatif & Nilai & $\begin{array}{c}\text { Alternatif } \\
\text { pilihan }\end{array}$ \\
\hline Biogas & 43 & Berpotensi \\
$\begin{array}{l}\text { Daur Ulang Air } \\
\text { Kolam pemandian ternak } \\
\text { dan pembersihan alas }\end{array}$ & 41 & Berpotensi \\
ternak & 42 & Berpotensi \\
\hline $\begin{array}{l}\text { Sumber : Data primer diolah (2018) } \\
\end{array}$ &
\end{tabular}

Alternatif biogas, daur ulang air, dan kolam pemandian ternak dan pencucian alas ternak sangat mudah untuk diterapkan (Tabel 5). Hal tersebut dikarenakan adanya SDM dan pengadaan bahan baku yang tersedia di CV. Margo Utomo. Ketiga alternatif ini sangat mudah untuk diterapkan dan memberikan manfaat yang lebih untuk CV. Margo Utomo.

\section{Analisis Lingkungan}

Analisis lingkungan digunakan untuk melihat apakah alternatif produksi bersih memberikan efek signifikan terhadap perbaikan atau tidak terhadap lingkungan. Jumlah indikator yang digunakan sebanyak 9 parameter yaitu kerusakan lingkungan, jumlah limbah yang di daur ulang, jenis limbah, penanganan limbah (padat, cair dan pengelolaan limbah), efek perbaikan lingkungan, \% penghematan, dan \% menghasilkan limbah setelah dilakukan penanganan. Skor 3 menunjukkan jika alternatif memberikan efek yang signifikan terhadap lingkungan, skor 2 untuk memberikan sedikit efek perbaikan lingkungan, dan skor 1 tidak memberikan efek terhadap perbaikan lingkungan. Tabel 6 merupakan hasil analisis lingkungan dari masing-masing alternatif.
Tabel 6. Hasil analisis lingkungan

\begin{tabular}{lcl}
\hline Alternatif & Nilai & Alternatif pilihan \\
\hline Biogas & 21 & Cukup Berpotensi \\
Daur ulang air & 21 & Cukup Berpotensi \\
$\begin{array}{l}\text { Kolam pemandian } \\
\text { ternak dan pencucian }\end{array}$ & & \\
$\begin{array}{l}\text { alas ternak } \\
\text { Sumber : Data primer diolah (2018) }\end{array}$
\end{tabular}

Analisis lingkungan untuk pembuatan biogas dan daur ulang air memberikan cukup efek perbaikan lingkungan, karena rata-rata jumlah nilai total berdasarkan aspek lingkungan untuk biogas adalah 21. Hal tersebut karena dalam pembuatan biogas menghasilkan gas, untuk kebutuhan memasak/kegiatan lainnya. Pada daur ulang air jumlah limbah yang dihasilkan hanya berupa limbah padat dari hasil filtrasi. Dengan mendaur ulang air, dapat mengurangi kandungan bahan pencemar. Dengan mendaur ulang air, limbah hasil filtrasi bisa digunakan kembali atau dibuang ke lingkungan dengan aman, tanpa menyebabkan kerusakan. Kolam pemandian ternak dan pencucian alas ternak jika di lihat dari aspek lingkungan, memberikan cukup efek perbaikan terhadap lingkungan karena nilai 16. Hal tersebut dikarenakan manfaat dari kolam ini hanya mengurangi jumlah air yang digunakan untuk setiap harinya tanpa dilakukan penanganan dan masih mengasilkan 2 jenis limbah yaitu padat dan air.

\section{Analisis Ekonomi}

Analisis ekonomi digunakan untuk menentukan apakah penerapan produksi bersih dapat terus dilanjutkan atau tidak. Analisis ekonomi dilihat dari nilai NPV, IRR, B/C Ratio dan PBP. Berikut merupakan analisis ekonomi dari masingmasing alternatif tindakan produksi bersih. 


\section{Biogas}

Tabel 7 merupakan hasil perhitungan ekonomi pembuatan biogas dalam satu tahun. Pembuatan biogas ini diasumsikan digunakan untuk memenuhi kebutuhan gas untuk keperluan memasak.

Tabel 7. Hasil perhitungan pembuatan biogas

\begin{tabular}{clc}
\hline No. & Total biaya & Jumlah \\
\hline 1 & Harga Biogas per $\mathrm{m}^{3}$ & Rp. 798 \\
2 & NPV & Rp 64.535.856 \\
3 & IRR & $28 \%$ \\
4 & B/C Ratio & 2,41 \\
5 & PBP & 4 bulan \\
\hline
\end{tabular}

Sumber : Data primer diolah (2018)

Keterangan: Net Present Value (NPV), Internal Rate of Return (IRR), Net Benefit Cost Ratio (B/C Ratio), dan Pay Back Period (PBP)

Berdasarkan pada hasil perhitungan ekonomi, alternatif pembuatan biogas dapat dilanjutkan. Hal tersebut dilihat dari hasil perhitungan NPV yang lebih besar dari pada satu, B/C Ratio > 1, yang dinyatakan layak dan dan waktu yang diperlukan untuk mengembalikan investasi awal (PBP) yang hanya 4 bulan.

\section{Daur Ulang Air}

Limbah cair sebanyak 6500 liter setelah dilakukan proses filtrasi akan berkurang menjadi 6490 liter. Menurut Indrasti dan Fauzi (2009), pengurangan tersebut disebabkan adanya bahan-bahan pengotor seperti kotoran ternak yang mengendap dan tersaring sehingga air bersih yang dihasilkan akan berkurang 10 liter. Tabel 8 merupakan hasil perhitungan ekonomi dari daur ulang air.

Secara ekonomi alternatif daur ulang air limbah cair peternakan layak untuk dilakukan atau diterapkan sesuai dengan Tabel 8. Hal tersebut dapat dilihat dari hasil perhitungan IRR yang memiliki nilai lebih besar dengan suku bunga yang berlaku dan B/C Ratio yang lebih besar dari 0 sehingga proyek layak untuk dilanjutkan.

Tabel 8. Hasil perhitungan daur ulang air

\begin{tabular}{clc}
\hline No. & Total biaya & Jumlah \\
\hline 1 & NPV & Rp 89.199 .354 \\
2 & IRR & $37 \%$ \\
3 & B/C Ratio & 1,37 \\
4 & PBP & 1 minggu \\
\hline
\end{tabular}

Sumber : Data primer diolah (2018)

Keterangan: Net Present Value (NPV), Internal Rate of Return (IRR), Net Benefit Cost Ratio (B/C Ratio), dan Pay Back Period (PBP)

Kolam Pemandian Ternak dan Pembersihan Alas Ternak

Pada kolam pemandian ternak dan pembersihan alas ternak, tidak dilakukan perhitungan ekonomi melainkan dihitung besar penghematan biaya karena tidak menghasilkan pendapatan. Besar penghematan untuk kolam pemandian ternak dan pembersihan alas ternak adalah Rp. 1.276.074.

\section{Pemilihan Alternatif}

Tabel 9 menunjukkan beberapa pemilihan alternatif yang berpotensi untuk diterapkan di peternakan CV. Margo Utomo. Pemilihan alternatif produksi bersih didasarkan pada tiga aspek yaitu teknis, lingkungan dan ekonomi untuk setiap alternatif.

Tabel 9. Pemilihan alternatif

\begin{tabular}{ccccc}
\hline \multirow{2}{*}{ Opsi } & \multicolumn{3}{c}{ Penilaian Opsi } & \multirow{2}{*}{ Alternatif } \\
\cline { 2 - 4 } & Teknis & Lingkungan & Ekonomi & \\
\hline B & Berpotensi & $\begin{array}{c}\text { Cukup } \\
\text { Berpotensi }\end{array}$ & Layak & 1 \\
D & Berpotensi & $\begin{array}{c}\text { Cukup } \\
\text { Berpotensi }\end{array}$ & Layak & 2 \\
$\mathrm{~K}$ & Cukup & $\begin{array}{c}\text { Cukup } \\
\text { berpotensi }\end{array}$ & $\begin{array}{c}\text { Tidak } \\
\text { layak }\end{array}$ & 3 \\
\hline
\end{tabular}

Sumber : Data primer diolah (2018)

Keterangan: B : biogas, D : daur ulang air, $\mathrm{K}$ : kolam pemandian ternak dan pencucian alas ternak 
Tabel 9 menunjukkan jika alternatif produksi bersih yang layak diterapkan atau berpotensi di peternakan CV. Margo Utomo adalah pembuatan biogas dan daur ulang air. Namun alternatif biogas lebih profit untuk diterapkan karena dapat memenuhi kebutuhan gas untuk memasak di cooling dan restoran.

\section{KESIMPULAN}

Karakteristik limbah cair peternakan langsung memiliki suhu $23,4^{\circ} \mathrm{C} ; \mathrm{pH} 8,1$; TDS 1307; TSS 508,4; Kekeruhan 476,8; COD 2134; dan BOD 1203,3. Sedangkan untuk limbah cair tampungan untuk suhu 25, $2^{\circ} \mathrm{C}$; pH 7,3; TDS 191,0; TSS 304,4; Kekeruhan 210,2 ; COD 1300; dan BOD 406,4. Nilai tersebut masih melebihi baku mutu limbah cair bagi usaha dan atau kegiatan peternakan sapi perah berdasarkan Peraturan Menteri Lingkungan Hidup Republik Indonesia Nomor 5 Tahun 2014.

Penerapan produksi bersih yang berpotensi untuk diterapkan di peternakan sapi perah CV. Margo Utomo adalah pembuatan biogas dan daur ulang air. Namun alternatif biogas lebih profit untuk diterapkan, karena dapat mencukupi kebutuhan memasak di cooling dan restoran. Kelayakan teknis untuk ketiga alternatif berpotensi untuk dilakukan, dengan kelayakan lingkungan untuk alternatif biogas dan kolam pemandian ternak dan pencucian alas ternak cukup berpotensi dan daur ulang air berpotensi. Sedangkan hasil dari analisis ekonomi untuk alternatif biogas yaitu NPV Rp 64.535.856; IRR 28\%;Net B/C 2,41; PBP 4 bulan. Daur ulang air dengan NPV Rp 89.199.354; IRR $37 \%$;Net B/C 1,37 ; PBP 1 minggu. Penghematan kolam pemandian ternak dan pencucian alas ternak adalah Rp. 1.276.074.

\section{DAFTAR PUSTAKA}

Ako, A. 2012. Ilmu Ternak Perah Daerah Tropis $2^{\text {nd }}$. IPB Press, Bogor.
Badan Pusat Statistik . 2016. Output tabel dinamis (Populasi sapi perah menurut Provinsi).

(https://www.bps.go.id/linkTableDinami s/view/id/1017.) [Diakses tanggal 2 Maret 2017].

Departemen Pertanian. 2000. Sanitasi kandang sapi perah. (http://pustaka.litbang.pertanian.go.id/ag ritek/lip50120.pdf). [Diakses tanggal 15 November 2017].

Hadiyanto. Purwanto. dan Widyastuti, F. R. 2013. Upaya pengelolaan lingkungan usaha peternakan sapi di kawasan usaha tani terpadu Bangka Botanical Garden Pangkalpinang. Prosiding Seminar Nasional Pengelolaan Sumber Daya Alam dan Lingkungan.

Indrasti, N. dan Fauzi, A. 2009. Produksi Bersih. IPB Press, Bogor.

Kementerian Lingkungan Hidup. 2017. Kebijakan produksi bersih di Indonesia. (http://www.menlh.go.id/kebijaksanaanproduksi-bersih-di-indonesia). [ Diakses tanggal 26 Maret 2017].

Peraturan Menteri. 2014. Baku mutu air limbah. Kementerian Lingkungan Hidup Republik Indonesia. (http://www.pelatihanlingkungan.com/w p-content/uploads/2015/01/Permen-LH5-2014-tentang-Baku-Mutu-Airlimbah.pdf). [Diakses tanggal 1 Februari 2017].

Peraturan Mentri Pertanian. 2006. Pedoman pembibitan sapi perah yang baik. (http://bibit.ditjenpkh.pertanian.go.id/sit es/default/files/PedomanPembibitanSapi PerahyangBaik.pdf). [Diakses tanggal 11 Juli 2018].

Putra, A. 2009. "Potensi Penerapan Produksi Bersih Pada Usaha Peternakan Sapi Perah (Studi Kasus Pemerahan Susu Sapi Morea Kudus Jawa Tengah)". Skripsi. Program Studi Ilmu Lingkungan, Universitas Diponegoro, Semarang. 
Sudiarto, B., 2008. Pengelolaan limbah peternakan terpadu dan agribisnis yang berwawasan lingkungan. Seminar Nasional Teknologi Peternakan dan Veteriner 2008, pp.52-60.

Sumiarsa, Jatnika, Kurnani, dan Lewaru. 2011. Perbaikan kualitas limbah cair peternakan sapi perah oleh Spirulina sp. Jurnal Akuatika, 2 (2): 91-93. 